\title{
Varia
}

\section{STD Meeting}

Rotterdam, May 10 and 11, 1976

On Monday the 10th and Tuesday the 11th of May 1976 a meeting on the subject 'Sexually Transmitted Diseases' will be held at the Medical Faculty of the Erasmus University Rotterdam. This conference is organized by the Department of Dermatology Contributions will be made by British, Scandinavian and American research workers in the STD field.

The preliminary program is made up as follows:

Monday: a.m. Immunology in syphilis (Chairman: H.E. Menke);^.^. Gonorrhoea (Chairman: G.R.W. Harris). Tuesday a.m. Main principles of health education about STD (Chairman: H. Verkleij); p.m. Chlamydia (Chairman: J. Wallin).

Secretary: E. Stolz.

Those who are interested in the definite program and the terms of subscription may apply to the Secretary of the Department of Dermato-Venereology, Academisch Ziekenhuis RotterdamDijkzigt, Dr. Molewaterplein 40, Rotterdam; Tel. 010/36 2000 (2874/4861). 